\title{
Towards an Open Model for Data Center Research: from CPU to Cooling Tower
}

\author{
Gulnara Zhabelova ${ }^{1}$, Mattias Vesterlund $^{2}$, Sascha Eschmann $^{3}$, Valeriy Vyatkin ${ }^{1,4}$, Damien Flieller $^{3}$ \\ ${ }^{1}$ Department of Computer Science, Electrical and Space Engineering \\ Lulea University of Technology, 97187 Lulea, Sweden. Email: name.surname @ 1tu.se \\ ${ }^{2}$ RISE SICS North, 973 47, Luleå, Sweden. Email: mattias.vesterlund@ri.se \\ ${ }^{3}$ National Institute of Applied Sciences, Strasbourg, France. Email: eschmann.sascha@gmail.com, amien.flieller@insa-strasbourg.fr \\ ${ }^{4}$ Department of Electrical Engineering and Automation, Aalto University, 02150, Helsinki, Finland \\ vyatkin@ieee.org
}

\begin{abstract}
Data centers are important players in the energy infrastructure. Aiming at addressing environmental challenges, large data centers such as Facebook, Google, Yahoo, etc., are increasing share of green power in their daily energy consumption. Such trends drive research into new directions, e.g. sustainable data centers. The research often relies on expressive models that provides sufficient details however practical to re-use and expand. There is a lack of available data center models that capture dynamics of the facility from the CPU to the cooling tower. It is a challenge to develop a model that allows to describe complete data center of any scale including its connection to the grid. This paper proposes such a model building on existing work. The challenge was to put the pieces of data center together and describe dynamics of each element so that interdependencies between components and parameters are captured correctly and in sufficient details. The proposed model was used in the project "Data center microgrid integration" and proven to be adequate and important to support such study.
\end{abstract}

Keywords-data center, model, cooling, server, CRAH, chiller, cooling tower, smart grid, microgrid.

\section{INTRODUCTION}

With the increasing expansion of information and communication technologies (ICT), the data center facilities are becoming a sizable part of the energy system. In the period 20072012 , electrical consumption of data centers had $4 \%$ annual growth [1].

In line with the general trend of environmental friendly development, the data centers owners have an interest in providing green services to their customers, including use of renewable energy sources to the greatest extent as possible. The intermittence in renewable energy sources such as solar and wind is a challenge. Data center can use energy storage and electrical grid as a backup for the variability in energy supply. Applying renewable energy sources to a data center drives new and interesting avenues, like the interplay between solar power and free cooling [2][5].

Data center models in various forms are used in such research studies. DCeET tool [4] showed the effect of climate zones, temperature and humidity on data center energy performance. Through reference model developed using TRNSYS [5], authors showed the effect of the location on operation and associated environmental impact of data center. A three-floor data center building was simulated in the eQUEST software for the evaluation and analysis of free cooling in different climate zones [6]. A dynamic energy model was created using TRNSYS for finding the best cooling configuration for liquid cooled servers, where the excess heat was used for heating a swimming pool [7]. By making complete data center models including predictions of computer workload, available renewable energy, battery state of charge and cost of electricity, a significant reduction in operation cost and $\mathrm{CO}_{2}$ footprint is shown to be feasible [3]. Authors of [8] highlight that while current data center models include workload management, cooling and power supply systems; the direction of development should be towards models that includes storage units, energy leakages, energy transfer costs and power transmission network structure.

The new research agendas require expressive, practical models of data center that allows to see impact throughout the facility. For example, effect of sustainable energy supply on the performance of server rooms (IT task deadlines, capacity, etc.) and operation of cooling equipment and regional power grid.

Often in the literature, models capture only aspects of data center that is of interest for the study: e.g. models of multi-core CPUs; or model of Computer Room Air Handling (CRAH) unit; models of server rooms [11] or IT task scheduling [19]. Some papers describe complete data center from server room to cooling tower [9][10]. However, those models do not provide enough insights into the data center dynamics (e.g. temperatures and air/waterflows) or their descriptions lack details to reproduce the models. Many models are not open and not available for others to use. Some models that are data driven, i.e. some parameters are not calculated, instead supplied by the prerecorded data from an existing facility. Here some interesting dependencies and dynamics can be lost and often such data is not openly available.

There is a gap when it comes to available data center models for research. It is a challenge to develop a practical yet detailed complete model of a data center that captures its operation from CPU of the individual servers to cooling tower of the facility. There is need for a model that allows to describe complete facility of any scale including its connection to the power grid.

The paper proposes a coherent model of data center that describes the complete facility: the surrounding power grid, electrical infrastructure, cooling system, server room and individual servers down to CPU. The authors also placed the model into the microgrid setting with local solar generation and battery. 
Such a model will allow to study the impact of user behavior (IT load) and IT infrastructure on dynamics of data center facility (e.g. air-/water-flow, temperatures, power, performance), and on its microgrid and power grid; or impact of grid disturbances on server performance and user satisfaction.

The paper is structured as follows: section II provides an overview of the proposed model, followed by description of the models of server room (III.A) and servers that include single and multi-core CPUs (III.B); the model allows to describe types of jobs that are performed by the server, this affects performance and capacity of the servers (III.C). Section IV describes models of cooling elements CRAH, chiller and heat exchanger and cooling tower. Model of microgrid is briefly described in section $\mathrm{V}$, where also the case study and results of the simulation are presented. The conclusion provides the final remarks and outlines the future work.

\section{OVERVIEW OF THE PROPOSED DATA CENTER MODEL}

The model represents a typical data center with a server room and a cooling system. In the server room, servers are arranged into rows of racks; and CRAH (Figure 1). The cooling system comprises of CRAH, chiller, cooling tower and pumps that control the water flow.

The model captures dynamics of the data center in a simplified practical manner focusing on configuration of servers, power consumption and cooling system dynamics.

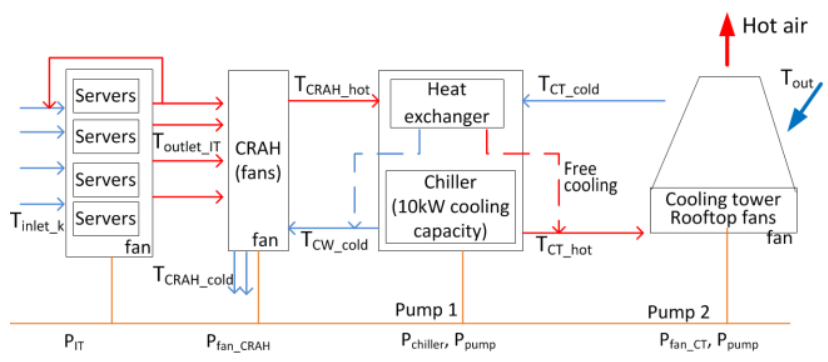

Figure 1. Overview of the data center model.

The model does not account for server rooms with perforated floors and cold- or hot- aisle containment. The available data and capability of the model are summarized in Table 1.

Table 1. Data center model capabilities.

The model provides monitoring of the following data:

Temperatures: inlet and outlet of individual servers and server rack, CRAH air and water; chiller water on user and source side, cooling tower water and outside temperature

Flows: airflow in the individual servers, server racks, and CRAH units; water flow in CRAH, chiller and cooling tower

Power consumption: individual servers, racks, server rooms, CRAH, chiller, cooling tower, fans and pumps;

Cooling dynamics: overload of CRAH, chiller and cooling tower (capacity,

load, remaining heat)

Efficiency and load: Utilization and coefficient of performance (COP) of the servers and equipment; Power usage effectiveness (PUE)

Server: task distribution; capacity and frequency

The model allows to capture:

Individual configuration of servers. Racks, CRAH, chiller and cooling tower

CRAH arrangements (e.g. Rack Location Unit, RLU, in-row cooling)

Failure in the cooling system: CRAH, chiller, cooling towers, fans and pumps

Free cooling

IT load distribution strategies (including IT load shifting)

Weather impact

IT job classification

\section{MODELS WITHIN THE SCOPE OF SERVER ROOM}

\section{A. Model of a server room}

The data center that is considered here is on a concrete floor and does not have cold- or hot-aisle containment

Within a server room typically there are racks of servers and network equipment, cables, cooling units and power distribution units. This model focuses on capturing power consumption and cooling related data of the data center. Therefore, only servers, racks and cooling equipment are considered in the model.

The model can be extended to consider size of the server room, occupancy of the offices; heat produced, and power consumed by the lighting, fire protection and alarm (monitoring) systems.

The considered room has servers that are arranged into racks. Sometimes, the servers are put into enclosures and then into the rack. The model will need to be configured accordingly.

The model of the server room is presented in the Table 2. The power consumption of the server is assumed to be linear and depends on the utilization of the server (CPU). The power consumed by the server defines the required airflow [12][13]. Commonly, there are four fans in a server, hence to calculate its power consumption, the airflow is divided by the number of fans. The power consumption of a fan is found by using impedance and fan performance curves.

Table 2. Model of the server room

\begin{tabular}{|c|c|}
\hline$P_{\text {server }}=P_{\text {idle }}+\left(P_{\max }-P_{\text {idle }}\right) U \%$ & $\mathrm{~W}$ \\
\hline$P_{\text {rack }}=\sum_{i=1}^{N s_{-} r} P_{\text {server }}$ & $\mathrm{W}$ \\
\hline$f_{\text {air_server }}=1.78 * \frac{P_{\text {server }}}{\Delta t} \cdot 0.000468,[13]$ & $\mathrm{m}^{3} / \mathrm{s}$ \\
\hline$f_{\text {air_fan_s }}=\frac{f_{\text {air_server }}}{N_{F}}$ & $\mathrm{~m}^{3} / \mathrm{s}$ \\
\hline$P_{\text {fan_server_s }}=\frac{f_{\text {air_fan__s }} \cdot P(P a)}{\eta}$, & $\mathrm{W}$ \\
\hline$P_{\text {fan_server }}=N_{F} \cdot P_{\text {fan_server_s }}$ & $\mathrm{W}$ \\
\hline$P_{\text {fan_rack }}=\sum_{i=1}^{N S_{-} r} P_{\text {fan_server }}$, & $\mathrm{W}$ \\
\hline$f_{\text {air_rack }}=\sum_{i=1}^{N s_{-} r}(1-k) \cdot f_{\text {air_server }}$ & $\mathrm{m}^{3} / \mathrm{s}$ \\
\hline$T_{\text {inlet_k }}=T_{\text {CRAH_cold }}+\frac{k \cdot P_{\text {rack }}}{f_{\text {air_rack }} \rho_{\text {air }} \cdot c_{\text {air }}}$, & ${ }^{\circ} \mathrm{C}$ \\
\hline$T_{\text {outlet_server }}=\frac{P_{\text {server }}}{f_{\text {air_server }} \cdot \rho_{\text {air }} \cdot c_{\text {air }}}+T_{\text {inlet_k }}$, & ${ }^{\circ} \mathrm{C}$ \\
\hline$T_{\text {outlet_rack }}=\frac{\sum_{i=1}^{N S} T_{\text {outlet_server }}}{N S_{\text {s } r} r}$ & ${ }^{\circ} \mathrm{C}$ \\
\hline$P_{I T}=\sum_{i=1}^{N} P_{\text {rack_i }}, P_{I T_{-} C R A H_{-} i}=\sum_{i=1}^{N_{\text {rack_per_CRAH }} P_{\text {rack_i }},}$, & $\mathrm{W}$ \\
\hline$P_{\text {fan_IT }}=\sum_{i=1}^{N} P_{\text {fan_rack } \_}$, & W \\
\hline 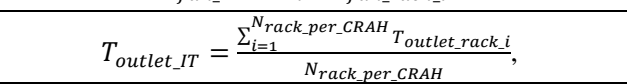 & ${ }^{\circ} \mathrm{C}$ \\
\hline$f_{\text {air_IT_CRAH_i }}=\sum_{i=1}^{N_{\text {rack_per_CRAH }}} f_{\text {air_rack_i }}$, & $\mathrm{m}^{3} / \mathrm{s}$ \\
\hline
\end{tabular}

The temperatures in a server room are calculated based on required temperature on the server intake, that is supplied by the CRAH. For instance, recommended by ASHRAE [14] temperature of the room is $22^{\circ} \mathrm{C}$. The air is heated when pushed through the server by fans and the resulting temperature depends on power consumed by the server, the created airflow and properties of the air. The model considers the re-circulation that can occur in a rack. The re-circulation index $k$ here denotes the fraction of air that comes from the server exhaust and recirculates and mixes with the cool room air supplied by CRAH units. $k=0$ implies no re-circulation, while $k=0.1$ suggests that 
$10 \%$ of the air is re-circulated. The inlet temperature of the servers then might be warmer than $22^{\circ} \mathrm{C}$ supplied by CRAH.

Typically, CRAH units are positioned to face several rows of racks. In this model, we consider the load of each CRAH unit as a number of racks that the CRAH unit is supposed to cool (circulate the cold air around). Similarly, in-row cooling [15][10] can be modelled by assigning the number of racks per CRAH unit. Alternatively, the cooling load of each CRAH can be calculated evenly by dividing the total server power in the room by the number of CRAH units. However, with our approach the variable heat density of the server room can be considered.

\section{B. Model of the server}

Since it is challenging to calculate power consumption of a server directly from the CPU frequency, as it also depends on the voltage and other parameters (1) [18], the power consumption of a server at various frequencies will be calculated indirectly, relative to the power consumption at $\max f$ (given) and current utilization (load) of the CPU (2). The total power can be split into dynamic $\left(P_{\text {transition }}\right.$ and $\left.P_{\text {short circuit }}\right)$ and static. $P_{\text {transition }}$ is due to current for charging and discharging the load capacitance $(C)$ formed by switching node from low to high state and vice versa (f). $P_{\text {short circuit }}$ results from short circuit current flowing during the dynamic switching activities, due to non-zero rise and fall times of the control signal. $P_{\text {static }}$ is due to the transistors leakage currents.

$$
\begin{gathered}
P_{\text {server }}=P_{\text {static }}+P_{\text {short circuit }}+P_{\text {transition }}=m V+\alpha \mathrm{E}_{\text {short circuit }} f+ \\
\quad \alpha \frac{1}{2} C V^{2} f \quad(1) \\
P_{\text {server }}=P_{\text {idle }}+\left(P_{\text {max }}-P_{\text {idle }}\right) \frac{U(\%)}{100}
\end{gathered}
$$

where $V$ is the operating voltage, $\alpha-$ is the number of transitions per clock cycle (activity factor), $m$ - is constant that captures number of transistors, design parameter and leakage current, $E_{\text {short circuit }}$ - power of a single short-circuit.

The proposed model of a server considers the resources that are available at the server. The resources that are used for processing IT jobs are processing cores, RAM, disk space and bandwidth. The proposed model allows to see the resulting power consumption of various task distribution strategies. In this model, memory usage is not considered at this stage, however intensive usage of memory can affect the power consumption of the server.

The servers in the model have 3 power states, though it can be customized to any number of states as per data sheet for a given CPU. P0 is often the highest performance state. P1 and $\mathrm{Pn}$ are successively lower-performance states. In states $\mathrm{P} 1-\mathrm{P} n$, voltage and frequency are scaled.

There are potential power savings of dynamic voltage and frequency scaling (DVFS). According to [12], in $2.4 \mathrm{GHz}$ system, savings are possible when CPU load is less than $2 / 3$ of peak by dropping the frequency to $1.8 \mathrm{GHz}$. Further $10 \%$ savings is achievable when utilization drops to $1 / 3$ by going to the frequency of $1 \mathrm{GHz}$. Further decline in the load $(<10 \%)$ the gains of dynamic voltage and frequency scaling are back to about $10 \%$ due to lack of proportionality in the system level.

The power consumption of each core is calculated in the same way as for the single core server, only the utilization is considered for each core. If even task distribution is implemented, then all cores will have the same utilization.

$$
\text { core tasks = current_tasks } / \mathrm{N} \_ \text {cores. }
$$

In the case of uneven task distribution, cores are loaded to the maximum first before loading the next core. So, the server can have one core loaded to $100 \%$ and other to $25 \%$ and rest are in the idle state.

The capacity of the server and utilization can be given in percentages (\%). In this model the capacity and load are calculated based on the tasks performed by the server. This method is described below.

\section{Job classification}

It is useful to consider job classification when studying impact of various task distribution methods on power consumption of the server. The size of the jobs and tasks, and their type will affect how much the server is loaded and for how long and therefore its consumption of power and energy. There are two types of jobs: batch jobs and service jobs [19]. Batch jobs are of a shorter duration (from minutes to hours). Service jobs consume resources over an extended period of time and have a priority over the batch jobs. Jobs are broken down into tasks, which is a smallest unit that are processed on the server. Jobs arrive at a particular rate and broken down to the tasks that are allocated to the servers.

In this model, the capacity of the server (CPU frequency) and utilization are calculated based on type and the size of jobs and the tasks. Below is an example of task definition, which is based on [20]. User of the model can define other size and type of the task that is more fit to the problem at hand.

Suppose that a task takes $5 \cdot 10^{5}$ instructions to execute. Out of these instructions $50 \%$ execute in 3 clock cycles; $30 \%$ in 4 clock cycles and $20 \%$ in 5 clock cycles. Hence, the execution time for a task is (3).

$$
T_{\text {exec }}=\frac{1}{f} \cdot 3.7 \cdot X
$$

where $f$ is the clock frequency of a core (CPU) and $X$ is the number of instructions in a task. Then, the speed of the core (server) in terms of tasks can be expressed as (4).

$$
\text { Speed }_{\text {tasks }}=\frac{f}{3.7 \cdot X} \text { tasks }_{\text {second }}
$$

Capacity of the core (CPU, server) in terms of tasks can be then expressed as (5).

$$
\text { Capacity }_{\text {tasks }}=\frac{f}{3.7 \cdot X} \text { tasks } / \text { second }
$$

Then, the jobs that are arriving at the data center, can be categorized in to 8 classes, similar to [19].

This job and task modeling and categorization is customizable or can be completely omitted in in the model. The utilization of the server then can be set as percentage (e.g. 20\%), where $100 \%$ is fully loaded server.

The model can include the job generator to simulate arrival of the jobs to the data center. The generator should output jobs at the defined job arrival rate $\lambda$, that belongs to one of the classes above and have assigned deadlines. The user can define the probability $p_{\text {class }}$ of a job belonging to a particular class. Then jobs with given arrival rate and class are broken down to the 
tasks. These tasks are characterized either in the similar manner as described above or in other way. These tasks then can be distributed to the machines.

\section{MODEL OF THE COOLING SYSTEM}

\section{A. Model of CRAH unit}

The CRAH unit considered in this model can be configured with the datasheet for a particular CRAH equipment.

The input to this model is temperature of the server outlet, required cold air temperature of the server room, temperature of the incoming cold water (or liquid) from the chiller, cooling load of the CRAH unit. Cooling load of the CRAH unit is the heat generated by the servers, that is the power consumed by the servers. The calculation of the cooling load of CRAH is described in section II.III. The re-circulation of the hot air is considered, if no re-circulation $k=0$.

From the datasheet of the CRAH unit, the following is required: performance curve (heat load vs water flow (and, if given, range)), air flow $\left(f_{\text {air_l }} T_{-} C R A H_{-} i\right)$ and fan efficiency and pressure drop. The latter two can also be taken from the ASHRAE recommendations.

First the water flow required to remove the heat is calculated. If the heat load is within the nominal capacity of the CRAH unit, then all heat is removed with the corresponding water flow. This can be found from the performance curve of the $\mathrm{CRAH}$, or other relevant data defined in the data sheet. The temperature of cold air $T_{\text {CRAH_cold }}$ (Figure 1) is calculated based on the outlet temperature of the server and reflects how much heat the CRAH unit can remove given the range (the difference between the cold water coming from the chiller and hot water returned by the CRAH unit). The range will impact how much heat can be removed and the water flow.

If the heat load exceeds the nominal capacity of the CRAH unit, not all heat is removed. The remaining heat stays with the air, implying that the $T_{C R A H}$ cold will be warmer than required $\left(22^{\circ} \mathrm{C}\right)$.

Once the heat that has been removed is known $\left(Q_{C R A H}\right.$ calc $)$, the temperature of the return warm water can be calculated $\left(T_{\text {CRAH_hot }}\right)$. The incoming hot air from servers are cooled by heating the cold water coming from chiller. $T_{C R A H \_h o t}$ is then derived from $T_{C R A H_{-} \text {cold }}$ based on the water flow and heat are calculated above in previous step.

This model includes $h$ - a heat transfer coefficient. This coefficient comes into play when the heat load exceeds the nominal capacity of the CRAH. If $h=0$, the CRAH only removes the nominal amount of heat and rest of the heat remains in the incoming air. However, there can be a case, when the excess heat transfers to the water. For example, if $h=0.1$, then $10 \%$ of the excess heat (that is what remains after the nominal amount of heat is removed), is spent to heat the water. This impacts the temperature of the water that is returned by CRAH to the chiller and the cold air supplied by CRAH. This allows to model failures of CRAH and chiller.

If the water from the chiller is coming very warm (range $=$ 0 ), the CRAH unit is out of its operating limits. In such a case, the CRAH unit is not able to cool the incoming air.
The aggregated water flow of all CRAH units constitutes the incoming water flow to the chiller. The temperature of the aggregated water from CRAH units is the average of water temperatures from each CRAH.

In this model power consumed by the CRAH is calculated based on COP, however, if the data for fans are known, it can be calculated as (6).

$$
P(\text { fan })=\frac{f_{\text {air } f l o w} \cdot P(P a)}{\eta} \quad \begin{aligned}
& \text { (6), where } \mathrm{P}(\mathrm{Pa}) \text { is the pressure drop and } \eta \text { is } \\
& \text { the efficiency }
\end{aligned}
$$

The aggregated heat that has been removed by the CRAH units $\left(Q_{C R A H_{-} \text {calc }}\right)$ is the heat load of the chiller $\left(Q_{\text {evap }}\right)$.

\section{B. Model of the chiller and heat exchanger}

The model of the chiller requires to be configured with the data from datasheet of the selected chiller. Data that is required are the operating limits of the chiller $\left(T_{C T \_h o t \_l i m i t}, T_{C W_{-} \text {cold_limit }}\right)$, water flow, pumps' efficiency and pressure drops.

The input to the model is temperature of the hot water coming from CRAH, required temperature of the cold water supplied to CRAH, aggregated water from required by CRAH, and the heat transfer coefficient $h$.

The first step is to calculate the temperature of the chilled water that is supplied to CRAH units. The hot water $T_{C R A H}$ hot cooled down by warming up the cold water coming from cooling tower $T_{C T_{-} \text {cold }}$ to the temperature $T_{C T_{-} \text {hot }}$. The heat is removed from the CRAH side and added to the cooling tower (CT) side.

If the heat load is within the nominal capacity of the chiller, then the calculation is straightforward. In the alternative case, only nominal amount of heat is removed from the hot water returned by CRAH units. The rest of the heat remains with the incoming water. If $h$ is considered, then a fraction of the remaining heat will be transferred to heat the water coming from CT.

The cooling load $\left(Q_{C T}\right)$ on to the $\mathrm{CT}$ is calculated as a sum of the heat removed by the chiller and the heat generated by the chiller.

The cool water coming from cooling tower is heated in the chilling process and the resulting temperature depends on cooling load to be removed, water flow at CT side and characteristics of the water (of the cooling liquid used).

The model will warn if the chiller starts operating outside the recommended operating limits. However, it will not stop, and parameters will continue to be calculated as described above, even they will exceed the allowed limits.

\section{Model of the cooling tower}

The model of the CT is based on the recommended practices by ASHRAE [21]. The model can be customized to fit selected CT.

The CT characterized by the range and approach temperature ( $\left.T_{\text {approach }}\right)$ [21]. Range is the difference between the water entering $\left(T_{C T_{-} h o t}\right)$ and leaving the CT $\left(T_{C T_{-} \text {cold }}\right)$. The approach is the difference between the leaving water temperature $\left(T_{C T_{-} \text {cold }}\right)$ and the outside air temperature $\left(T_{\text {out }}\right)$ and usually within $2.8^{\circ} \mathrm{C}<$ $T_{\text {approach }}<4^{\circ} \mathrm{C}$. The load of a CT $\left(\lambda_{\mathrm{CT}}\right)$ here is defined as a 
relation between water flow required by the chiller to remove the heat and the nominal water flow of the CT.

The $T_{C T_{-} \text {cold }}$ depends on outside temperature, range and load of the CT.

The model will warn if the hot water returning from chiller $\left(T_{C T_{-} h o t}\right)$ is too cold (in this case the range is taken as minimum $\left.4^{\circ} \mathrm{F}\right)$, or the water $\left(T_{C T_{-} h o t}\right)$ is too hot, in which case the range is taken as maximum $30^{\circ} \mathrm{F}$ ).

The power consumption of the CT can be calculated based on the fan characteristics (if known) or on COP.

The CT completes the model of the data center. The total power consumption of the data center can be calculated as in (7).

$$
P_{\text {total }}=P_{I T}+P_{\text {fan } \_I T}+P_{C R A H}+P_{\text {chiller }}+P_{C T}+P_{\text {pumps }}(7)
$$

The next section will present a case study to demonstrate the model in the selected configuration of the data center.

\section{CASE STUdy, Simulation AND RESUlts}

\section{A. Selected configuration of the data center}

The proposed model of the data center was applied within the project Data center Microgrid Integration (DMI) [22]. This project studies the feasibility and potential of the data center as a self-contained self-reliant unit. Data center is an operator of its microgrid, that comprises of renewable generation (solar), energy storage (battery), water tank storage for cooling and have a back up connection to the main grid. The proposed model is a good fit for such study.

The model of microgrid was developed to support the study (Figure 2). The microgrid contains: the regional power grid, the energy storage (battery, 30kWH), solar generation $(10 \mathrm{~kW})$, the data center $(10 \mathrm{~kW})$, an inverter, control and HMI panels. The challenge was to achieve acceptable power characteristics of the microgrid and develop a reversible AC-DC inverter model. The developed microgrid can operate in grid connected and islanded modes. However, the simulation is still slow. This issue will be investigated further.

The server configuration is selected as described in Table 4.

Table 4. Selected DMI server configuration for the simulation.

\begin{tabular}{|c|c|c|c|c|c|c|}
\hline $\begin{array}{c}\text { Frequency, } \\
\mathrm{Hz}\end{array}$ & \multicolumn{2}{|c|}{ Power states, Hz } & $\begin{array}{c}\text { Pidle, } \\
\text { f }\end{array}$ & $\begin{array}{c}\text { Pmax, } \\
\text { W }\end{array}$ & $\begin{array}{c}\text { N } \\
\text { cores }\end{array}$ & $\begin{array}{c}\text { Frequency } \\
\text { scaling }\end{array}$ \\
\hline $2.4 * 10^{9}$ & $1.8 \cdot 10^{9}$ & $1 \cdot 10^{9}$ & 138.8. & 277.7 & 6 & no \\
\hline
\end{tabular}

Selected configuration of the data center is detailed in Table 3. The following air and water properties are considered in the model [23][24]: air density $(\rho) 1.18 \mathrm{~kg} / \mathrm{m}^{3}$ at $25^{\circ} \mathrm{C}$; heat capacity of air (c) $1010 \mathrm{~J} /\left(\mathrm{kg}^{\circ} \mathrm{C}\right)$; water density $998.68 \mathrm{~kg} / \mathrm{m}^{3}$ at $20^{\circ} \mathrm{C}$; water heat capacity $4187 \mathrm{~J} /\left(\mathrm{kg}{ }^{\circ} \mathrm{C}\right)$.

\section{B. Simulation and results}

The microgrid is simulated in both grid connected and islanded mode. The operation of the microgrid is controlled by a programmable logic controller (PLC) (Figure 2). Data center, through the PLC, controls the battery and manages operation in both modes. The weather data is provided to the solar generation. Microgrid also monitors its own frequency and can detect overload/underload conditions.

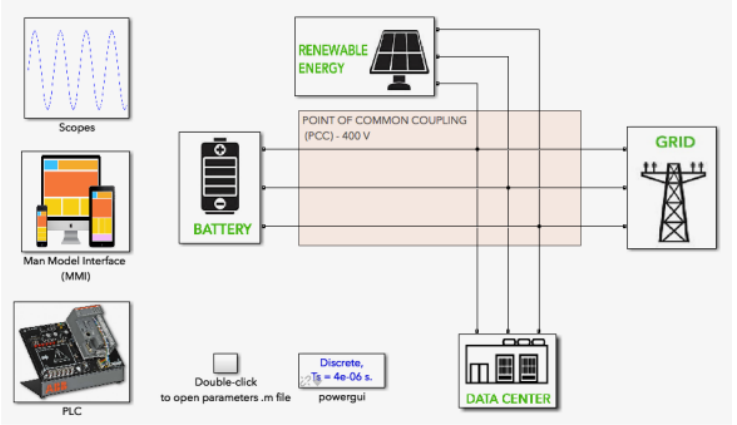

Figure 2. DMI data center microgrid model (Matlab Simulink).

In grid connected mode, the voltage level and the frequency are imposed by the grid. In that case, both inverters (battery and solar panels) are current controlled. In the following scenario: battery is charging, solar panel generates power (Figure 3).

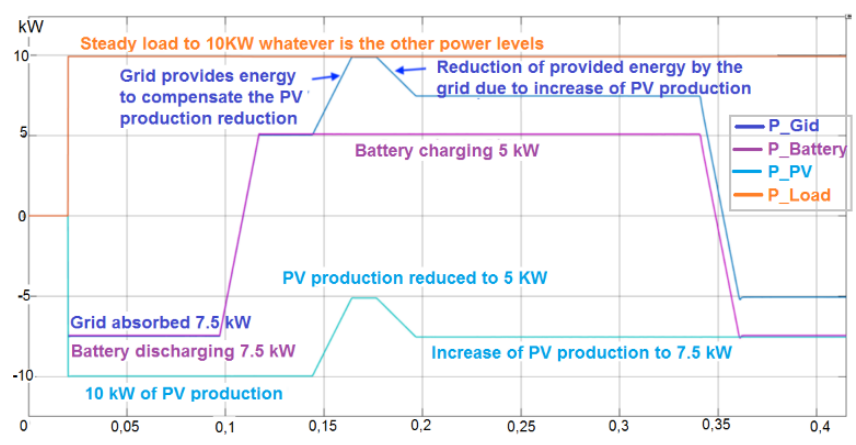

Figure 3. Active power flow in grid connected mode.

In islanded mode, the frequency and the voltage level are regulated by the inverter. Indeed, when both battery and photovoltaic source are producing energy, the inverter of the battery regulates the frequency level and voltage level through the droop-control method.

Below, the results are presented for one configuration of the data center (Table 4). This is due to page limitation of the paper and it is sufficient to demonstrate main capabilities of the model.

In the simulation, the utilization (IT load) of the server is steadily increased from idle to $100 \%$. To demonstrate overload of CRAH units, capacity of the servers was increased from 10 $\mathrm{kW}$ to $12.6 \mathrm{~kW}$ (Table 3. Selected data center configuration.). CRAH capacity $3.1 \mathrm{~kW}$, while one rack is $6.3 \mathrm{~kW}$, and one rack is shared between two CRAH, so each CRAH has $3.15 \mathrm{~kW}$ cooling load. Which means $50 \mathrm{~W}$ of heat remains with outgoing cold air $\mathrm{T}_{\mathrm{CRAH} \_ \text {cold. }}$

Figure 4 shows temperatures within data center. $\mathrm{CRAH}$ maintains $\mathrm{T}_{\mathrm{CRAH} \_ \text {cold }}$ at desired $22^{\circ}$. Once IT load reaches $100 \%$ and IT power consumption reaches $12.6 \mathrm{~kW}, T_{C R A H_{-} \text {cold }}$ and

Table 3. Selected data center configuration.

\begin{tabular}{|c|c|c|c|c|c|c|c|c|c|}
\hline \multicolumn{10}{|c|}{ Server room configuration } \\
\hline $\begin{array}{l}\text { Number } \\
\text { of servers }\end{array}$ & $\begin{array}{l}\text { Number } \\
\text { of racks }\end{array}$ & $\begin{array}{l}\text { Number of } \\
\text { CRAH units }\end{array}$ & $\begin{array}{c}\Delta \mathrm{T} \\
\text { (server) }\end{array}$ & $\mathrm{k}$ & $\begin{array}{c}\mathrm{P} \text { idle, } \\
\text { server room }\end{array}$ & $\begin{array}{l}\text { P max, server } \\
\text { room }\end{array}$ & $\begin{array}{l}\text { T outlet } \\
\text { (server) }\end{array}$ & Type of server & $\begin{array}{l}\text { Number of fans } \\
\text { in a server }\end{array}$ \\
\hline 36 & 2 & 4 & $12^{\circ} \mathrm{C}$ & 0 & $5 \mathrm{~kW}$ & $10 \mathrm{~kW}$ & $34^{\circ} \mathrm{C}$ & $\begin{array}{c}\text { Facebook Open } \\
\text { Compute }\end{array}$ & 4 \\
\hline \multicolumn{10}{|c|}{ CRAH unit, chiller and cooling tower configuration } \\
\hline $\mathrm{T}_{\mathrm{CW} \_ \text {cold }}$ & $\begin{array}{l}\text { CRAH } \\
\text { capacity }\end{array}$ & $\begin{array}{l}\text { Chiller } \\
\text { capacity }\end{array}$ & $\mathrm{T}_{\text {out }}$ & $\mathrm{T}_{\mathrm{CT}_{\text {C_cold }}}$ & $\mathrm{T}_{\mathrm{CT} \_ \text {hot }}$ & $\begin{array}{l}\text { Chiller water flow } \\
\text { (condenser) }\end{array}$ & $\begin{array}{l}\text { Cooling tower } \\
\text { capacity }\end{array}$ & \multicolumn{2}{|c|}{$\begin{array}{l}\text { Cooling tower characteristics by } \\
\text { ASHRAE guideline [21] }\end{array}$} \\
\hline $15^{\circ} \mathrm{C}$ & $3.1 \mathrm{~kW}$ & $12.9 \mathrm{~kW}$ & $20^{\circ} \mathrm{C}$ & $35^{\circ} \mathrm{C}$ & $40^{\circ} \mathrm{C}$ & $0.791 / \mathrm{s}$ & $13.6 \mathrm{~kW}$ & \multicolumn{2}{|c|}{$\mathrm{T}_{\mathrm{CT} \text { cold }} \mathrm{Vs} \mathrm{T}_{\text {out }}$} \\
\hline
\end{tabular}


$T_{\text {CRAH_hot }}$ start growing and reach $24^{\circ} \mathrm{C}$ to $36^{\circ} \mathrm{C}$. This is a slight increase, as the remaining heat is not much $(50 \mathrm{~W})$. The rest of temperatures are stable; cooling tower temperatures grow as load on cooling tower increases, since there is no free cooling $(\mathrm{P}$ chiller adding just under $5 \mathrm{~kW}$ ).

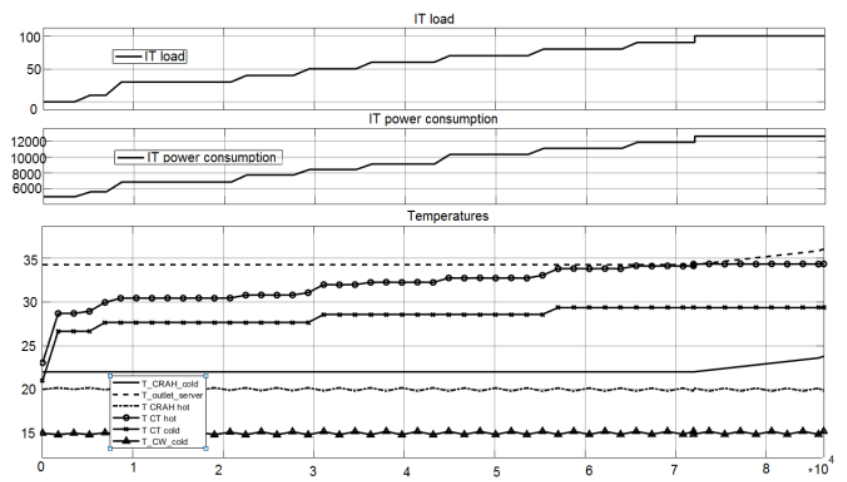

Figure 4. Data center with the 6-core servers (without frequency scaling): temperatures throughout server room and cooling system.

\section{CONCLUSION}

The paper proposed a comprehensive yet open model of data center, building on existing work. It captures configuration and dynamics of servers, server rooms, cooling systems (CRAH, chiller and cooling tower) and connection to the grid. The challenge was to put the pieces of data center together and describe dynamics of each element so that interdependencies between components and parameters are captured correctly and in sufficient details. The model can be used as is or configured with specific equipment. It can be used in various studies from impact of user behavior to data center as a smart load in the power grid.

The immediate next step is to extend model with water storage tank, that will enable some flexibility in cooling system. The future work includes modeling the job generator with patters of different online users (shopping, games, office work etc.). The model can be improved by the community adding more details in the thermodynamics area, server model (RAM, disk space, bandwidth), server room (perforated floors, cold or hot aisle containment) and more. The model is open and has capacity and potential to support new agendas in data center research.

\section{ACKNOWLEDGMENT}

This work was carried out within the project Data center Microgrid 2016-007959 supported by Energimydigheten, and project Sendate-Extend 2016-00717 supported by Celtic+ and Vinnova.

\section{REFERENCES}

[1] W. Van Heddeghem, S. Lambert, B. Lannoo, D. Colle, M. Pickavet, and P. Demeester, "Trends in worldwide ICT electricity consumption from 2007 to 2012," Comput. Commun., vol. 50, pp. 64-76, Sep. 2014.

[2] I. Goiri, W. Katsak, K. Le, T. D. Nguyen, and R. Bianchini, "Designing and Managing Data centers Powered by Renewable Energy," IEEE Micro, vol. 34, no. 3, pp. 8-16, May 2014.

[3] Í. Goiri, W. Katsak, K. Le, T. D. Nguyen, and R. Bianchini, "Parasol and GreenSwitch: Managing Datacenters Powered by Renewable Energy," in Proceedings of the eighteenth international conference on Architectural support for programming languages and operating systems - ASPLOS '13, 2013, p. 51.
[4] J. Cho and Y. Kim, "Improving energy efficiency of dedicated cooling system and its contribution towards meeting an energy-optimized data center," Appl. Energy, vol. 165, pp. 967-982, Mar. 2016.

[5] V. Depoorter, E. Oró, and J. Salom, "The location as an energy efficiency and renewable energy supply measure for data centres in Europe," Appl. Energy, vol. 140, pp. 338-349, Feb. 2015.

[6] K.-P. Lee and H.-L. Chen, "Analysis of energy saving potential of air-side free cooling for data centers in worldwide climate zones," Energy Build., vol. 64, pp. 103-112, Sep. 2013.

[7] E. Oró, R. Allepuz, I. Martorell, and J. Salom, "Design and economic analysis of liquid cooled data centres for waste heat recovery: A case study for an indoor swimming pool," Sustain. Cities Soc., vol. 36, pp. 185-203, Jan. 2018.

[8] T. Chen, X. Wang, and G. B. Giannakis, "Cooling-Aware Energy and Workload Management in Data Centers via Stochastic Optimization," IEEE J. Sel. Top. Signal Process., vol. 10, no. 2, pp. 402-415, Mar. 2016.

[9] S. Pelley, D. Meisner, T. F. Wenisch, J. W. Vangilder Understanding and abstracting total data center power, In Workshop on Energy-Efficient Design, 2009

[10] M. Zapater, A. Turk, J. M. Moya, J. L. Ayala and A. K. Coskun, "Dynamic workload and cooling management in high-efficiency data centers," 2015 Sixth International Green and Sustainable Computing Conference (IGSC), Las Vegas, NV, 2015, pp. 1-8.

[11] X. Zhang, T. Lindberg, K. Svensson, V. Vyatkin, A. Mousavi, "Power Consumption Modeling of Data Center IT Room with Distributed Air Flow," International Journal of Modeling and Optimization vol. 6, no. 1, pp. 33-38, 2016.

[12] Luis Andre Barroso; Jimmy Clidaras; Urs Hoelzle, "The Datacenter as a Computer: An Introduction to the Design of Warehouse-Scale Machines," in The Datacenter as a Computer:An Introduction to the Design of Warehouse-Scale Machines , 1, Morgan \& Claypool, 2013.

[13] Dell power solutions (2005), "Guidelines for assessing power and cooling requirements in the data center", Dell Inc., www.dell.com/downloads/global/power/ps3q05-20050115-Moss.pdf, August 2001, accessed January 2018.

[14] ASHRAE TC9.9 (2011). Thermal guidelines for data processing environments - expanded data center classes and usage guidelines. American Society of Hearing, Refrigirating, and Air-cooling Engineers.

[15] K. Dunkap, N. Rasmussen (2012). Choosing between Room, Row and Rackbased cooling for data centers. White paper 130, rev.2. APC, Data center Science Center DCSC Scheider-Electric.com.

[16] Rob Snevely. 2002. Enterprise Data Center Design and Methodology (First ed.). Prentice Hall Press, Upper Saddle River, NJ, USA.

[17] Sun Microsystems (2004), Site planning gude for entry level servers version 1.4. Chapter 4 System power and cooling requirements.

[18] A. Renbi (2009). Data - Stream - Driven computers are powe and energy efficient, Chapter 16 in Energy aware systems and Networking for sustainable initiatives, Information Science Reference (IGI Global), USA. pp361-375.

[19] T.T. Tran, J. C. Beck,. Report: Coogle data center scheduling. Department of Mechanical and Industrial engineering, University of Toronto.

[20] G.Shute, Lectures on Computer Architecture. CPU performance. University of Minnesota, Duluth, USA. www.d.umn.edu/ gshute/arch/arch.html, accessed October 2017.

[21] ASHRAE (2012). TC8.6 Cooling towers and evaporative condensers. Chapter 40. Cooling towers. American Society of Hearing, Refrigirating, and Air-cooling Engineers.

[22] Data center microgrid integration. Luleå University of Technology, Sweden, 2017-2018. www.energiforsk.se/program/smarta-elnat/projekt/ai-foroptimering-av-datacenter-microgrid-integration/ aceessed on May 2018.

[23] H. Hens (2012). Applied Building Physics: Boundary conditions, Building performance and Material Properties. Ernst\&Sohn Verlag, Berlin, Germany .

[24] P. E. Nilsson. (2003). Achieving the desired indoor climateL Energy efficiency aspects of system design. Studentlitteratur AB. Lund, Sweden 
